\title{
CIENCIAMATRIA
}

Revista Interdisciplinaria de Humanidades, Educación, Ciencia y Tecnología

Año VII. Vol. VII. N¹2. Enero - Junio. 2021

Hecho el depósito de ley: pp201602FA4721

ISSN-L: 2542-3029; ISSN: 2610-802X

Universidad Nacional Experimental Francisco de Miranda (UNEFM). Santa Ana de Coro. Venezuela

Sandra Margoth Cabrera-Encalada; Juan Carlos Erazo-Álvarez; Cecilia Ivonne Narváez-Zurita

Renán Teodoro Rodríguez-Pillaga

$\underline{\text { DOI } 10.35381 / \mathrm{cm} . v 7 i 12.446}$

\section{El Control Interno en la Gestión Administrativa de las Unidades Desconcentradas del Ejecutivo}

\section{Internal Control in the Administrative Management of Deconcentrated Executive Units}

\author{
Sandra Margoth Cabrera-Encalada \\ sandra.cabrera@est.ucacue.edu.ec \\ Universidad Católica de Cuenca, Cuenca \\ Ecuador \\ https://orcid.org/0000-0002-4081-3220 \\ Juan Carlos Erazo-Álvarez \\ jcerazo@ucacue.edu.ec \\ Universidad Católica de Cuenca, Cuenca \\ Ecuador \\ https://orcid.org/0000-0001-6480-2270 \\ Cecilia Ivonne Narváez-Zurita \\ inarvaez@ucacue.edu.ec \\ Universidad Católica de Cuenca, Cuenca \\ Ecuador \\ https://orcid.org/0000-0002-7437-9880 \\ Renán Teodoro Rodríguez-Pillaga \\ rtrodriguezp@ucacue.edu.ec \\ Universidad Católica de Cuenca, Cuenca \\ Ecuador \\ https://orcid.org/0000-0002-5456-5619
}

Recibido: 01 de octubre de 2020

Aprobado: 15 de diciembre de 2020 


\title{
RESUMEN
}

Los constantes cambios en el sector público y privado motivan a las instituciones a crear nuevas estrategias de gestión administrativa. El objetivo del presente artículo es realizar una propuesta de mejoramiento al sistema de control interno actual en la gestión administrativa de las unidades desconcentradas del poder ejecutivo, lo cual minimizará las deficiencias optimizando el uso de los recursos públicos. Metodológicamente fue de tipo descriptiva transversal. La propuesta aporta esencialmente a las unidades desconcentradas a conocer la normativa legal vigente, así como la planificación de actividades de cada unidad y su relación externa con otras instituciones para el desarrollo de la gestión administrativa.

Descriptores: Administración financiera; gestión de recursos; gestión del personal. (Palabras tomadas del Tesauro UNESCO).

\begin{abstract}
The constant changes in the public and private sectors motivate the institutions to create new administrative management strategies. The objective of this article is to make a proposal to improve the current internal control system in the administrative management of the decentralized units of the executive branch, which will minimize deficiencies by optimizing the use of public resources. Methodologically, it was descriptive crosssectional. The proposal essentially contributes to the decentralized units to know the current legal regulations, as well as the planning of activities of each unit and its external relationship with other institutions for the development of administrative management.
\end{abstract}

Descriptors: Financial administration; resources management; personnel management. (Words taken from the UNESCO Thesaurus). 


\section{CIENCIAMATRIA}

Revista Interdisciplinaria de Humanidades, Educación, Ciencia y Tecnología

Año VII. Vol. VII. N¹2. Enero - Junio. 2021

Hecho el depósito de ley: pp201602FA4721

ISSN-L: 2542-3029; ISSN: 2610-802X

Universidad Nacional Experimental Francisco de Miranda (UNEFM). Santa Ana de Coro. Venezuela

Sandra Margoth Cabrera-Encalada; Juan Carlos Erazo-Álvarez; Cecilia Ivonne Narváez-Zurita Renán Teodoro Rodríguez-Pillaga

\section{INTRODUCCIÓN}

Los constantes cambios en el sector público y privado como son los adelantos tecnológicos, entre otros motivan a las instituciones a crear nuevas estrategias de gestión administrativa acorde a los factores externos que las rodean. En este contexto el control interno constituye una de las columnas fundamentales de las entidades públicas, por cuanto es responsabilidad de cada organización estatal e instituciones privadas que administren recursos públicos siendo aplicable desde la máxima autoridad hasta cada servidor público de la entidad con el fin de precautelar los recursos públicos.

Son parte del control interno, el ambiente de control, el análisis de posibles problemas que puedan presentarse, los mecanismos utilizados para el control, así como los sistemas informáticos de comunicación y seguimiento. El control interno está orientado a cumplir con la normativa vigente, así como a promover eficiencia garantizando de esta manera la veracidad y oportunidad de la información, en base de ello, tomar los correctivos pertinentes que se presenten en la gestión administrativa (Celi de la Torre, 2019). La falta de confianza por parte de los usuarios del servicio público, ha conducido a las instituciones públicas a mejorar la administración pública, existen reformas a la normativa con el fin de mejorar el control interno y servicio al usuario, en las cuales intervienen los organismos de control como, por ejemplo, La Contraloría General del Estado, siendo las atribuciones más importantes, presidir los procedimientos de control administrativo, existiendo en cada entidad la unidad de auditoría interna y de control interno de las instituciones públicas y de aquellas que estén conformadas en sus aportes por dineros públicos, definir compromisos administrativos sobre la gestión y sanciones civiles culposas, así como vestigios de responsabilidad penal relacionadas con los aspectos sujetos a su control, sin la Fiscalía General del Estado pierda sus atribuciones en lo que es competente (Asamblea Constituyente, 2008).

La desconcentración de las unidades del poder ejecutivo, es el traslado de ciertas y determinadas facultades y atribuciones desde el nivel central hacia otros niveles jerárquicamente dependientes; espacio en cual el nivel central conserva la autoridad 
garantizando el servicio al usuario externo, aplicando los procedimientos legales y reglamentarios cuyo objetivo es garantizar los derechos ciudadanos a través de la prestación de servicios públicos con eficiencia, calidad y calidez, lo cual beneficia a la población por cuanto los servicios son cercanos a la ciudadanía para garantizar cobertura y calidad con acceso permanente, optimizando los recursos públicos.

Con estos lineamientos, se plantea un modelo de gestión que procure servicios en el territorio, sean desconcentrados o descentralizados, cuyo propósito final es construir un territorio más equitativo, logrando redistribución administrativa y política en el territorio, y sobre todo garantizando que la ciudadanía goce de sus derechos a través de servicios oportunos, cercanos, con calidad y calidez.

La problemática se evidencia por la falta de un control adecuado en el uso de los bienes públicos de larga duración como son los vehículos, equipos tecnológicos y muebles lo cual conlleva a egresos innecesarios de recursos económicos, pudiendo estos ser utilizados en otros procesos de contratación pública que permitan brindar un mejor servicio al usuario externo como interno (Muñoz, 2014).

El objetivo del presente artículo es realizar una propuesta de mejoramiento al sistema de control interno actual en la gestión administrativa de las unidades desconcentradas del poder ejecutivo, lo cual minimizará las deficiencias mejorando los resultados de la gestión administrativa, optimizando el uso de los recursos públicos.

\section{Referencial Teórico}

\section{El Control Interno como Herramienta de Gestión Administrativa de las Unidades Desconcentradas del Ejecutivo}

El sistema de control interno comprende, las políticas, normas y procedimientos ejecutados por la administración con el fin de garantizar la gestión de la institución de manera ordenada y eficiente, precautelar la documentación generada propia de las actividades desarrolladas por las instituciones tanto administrativa como financiera, la 


\section{CIENCIAMATRIA \\ Revista Interdisciplinaria de Humanidades, Educación, Ciencia y Tecnología \\ Año VII. Vol. VII. N¹2. Enero - Junio. 2021 \\ Hecho el depósito de ley: pp201602FA4721 \\ ISSN-L: 2542-3029; ISSN: 2610-802X \\ Universidad Nacional Experimental Francisco de Miranda (UNEFM). Santa Ana de Coro. Venezuela \\ Sandra Margoth Cabrera-Encalada; Juan Carlos Erazo-Álvarez; Cecilia Ivonne Narváez-Zurita \\ Renán Teodoro Rodríguez-Pillaga}

integridad de los registros contables e información financiera oportuna (Chiavenato, 2004).

Promover, optimizar y transparentar la gestión de la Institución, así como la calidad del servicio que brinda al usuario externo. Precautelar los recursos económicos y bienes del Estado evitando de esta manera la pérdida, deterioro y mal uso de los mismos, aplicando la normativa vigente y los reglamentos internos de las diferentes instituciones en todas sus actividades, promoviendo las buenas prácticas por parte de los servidores públicos de rendir cuentas por los fondos y bienes públicos entregados (Estrada, 2010).

Dentro del control interno existen cuatro categorías establecidas, de objetivos, de tipo estratégico, de información financiera, de operaciones y de cumplimiento de las disposiciones legales y reglamentarias, cada una de ellas se encargan de temas definidos para conseguir los objetivos requeridos, no obstante, el control interno encaminado a la información financiera es el que permitirá llevar adelante la auditoria de estados financieros basados en la información de relevancia para la entidad.

El control interno es favorable para la entidad por cuanto permite la consecución de objetivos en base a los cambios que se implementan. Entre los principales beneficios se puede mencionar: promueve la optimización de gestión institucional tanto a nivel administrativo como de otros espacios de la entidad, evitar la corrupción, fortalece a la institución para conseguir sus objetivos evitando la pérdida de recursos, asegura que la entidad cumpla con la normativa vigente permitiendo mantener la imagen institucional positiva ante el usuario interno y externo. En conclusión, el control interno contribuye con la entidad a cumplir sus metas, evitando inconvenientes en cada ejercicio fiscal (Estrada, 2010).

Según (Martillo, 2008), la implementación y fortalecimiento del control interno, promueve: la toma de decisiones en base a indicadores, mejora la ética institucional al promover la aplicación de la normativa vigente, la aplicación eficiente de los planes estratégicos, así como de los procesos, la buena práctica de la cultura de medición de resultados por parte 
por parte de todas las dependencias de las instituciones, minimiza las pérdidas por mal uso de bienes públicos. Implementar políticas de control apropiadas para cada entidad lo cual posibilitará el empleo adecuado de los dineros públicos a fin de conseguir una gestión financiera y administrativa enfocada en los objetivos institucionales, alcanzando el perfeccionamiento de la productividad y servicio a la colectividad

Según (Poch, 2000), el Control Interno se define como la estructura por medio de la cual una entidad implanta los principios, métodos y procedimientos cuyo objetivo es precautelar los recursos de la institución a fin de evitar y descubrir fraudes y errores al interior de las organizaciones en cada una de los departamentos que la componen.

Además, el control interno forma parte de un proceso conjunto a ser llevado adelante por parte de las autoridades, así como de los servidores de las entidades, enfocados al cumplimiento de las funciones de: proteger los recursos de la organización, garantizar la eficacia y la eficiencia en todas las operaciones, cuidar de que las acciones, dineros y talento humano de la entidad estén encamino a los intereses institucionales, respaldar la gestión institucional, velar por la seguridad de la información generada en las entidades así como por la oportunidad de la misma, definir y ejecutar disposiciones a fin de evitar riesgos, descubrir y enmendar errores que puedan presentar las entidades y que podrían perjudicar a los intereses institucionales, proteger el sistema de control interno y que el mismo establezca mecanismos exclusivos de fiscalización y valoración. (CharryRodríguez, 2013).

Los sistemas de información integrantes de los elementos del control interno deben considerar, determinar de dónde proviene la información existente, para ello examinarán las clases de transacciones de importancia que afectan a la gestión administrativa, analizando de dónde provienen y su trascendencia financiera. En cuanto a la adquisición y tratamiento de la información se deben reconocer los procedimientos financieros para todos los movimientos contables, en referencia a la utilización de la información generada, se considerará la manera de transmitir los resultados financieros por parte de 


\begin{abstract}
CIENCIAMATRIA
Revista Interdisciplinaria de Humanidades, Educación, Ciencia y Tecnología

Año VII. Vol. VII. N¹2. Enero - Junio. 2021

Hecho el depósito de ley: pp201602FA4721

ISSN-L: 2542-3029; ISSN: 2610-802X

Universidad Nacional Experimental Francisco de Miranda (UNEFM). Santa Ana de Coro. Venezuela

Sandra Margoth Cabrera-Encalada; Juan Carlos Erazo-Álvarez; Cecilia Ivonne Narváez-Zurita

Renán Teodoro Rodríguez-Pillaga
\end{abstract}

la organización, los estados financieros y su relevancia dentro y fuera de la entidad de manera especial con los entes de control (Fonseca, 2011).

Las actividades de control pueden clasificarse en: preventivos, con el objetivo de evitar errores o irregularidades. De detección, para identificar errores posteriores a la ocurrencia con el objetivo de tomar medidas correctivas. De compensación, controles para brindar seguridad cuando no es posible la aplicación de controles directos. De dirección, para orientar a los servidores para el cumplimiento de los objetivos institucionales (Mantilla, 2008).

Los controles frecuentes a nivel operativo son: segregación de funciones, reduce la posibilidad de que un solo funcionario pueda ocultar errores o fraudes. Control de autorizaciones, define quién tiene la autoridad para aprobar diversas transacciones. Conciliación de cuentas, permite tomar decisiones en base a las diferencias que puedan presentarse. Controles de aplicación de TI: aplicados a los sistemas de información, los cuales son automatizados de acuerdo a la necesidad de cada institución. Revisión de resultados reales, comparar los resultados reales contra los presupuestados y períodos anteriores. Controles físicos, se refiere a la constatación física de los activos, verificar la seguridad de los mismos, acceso a instalaciones, registros contables, entre otros (Martillo, 2008).

El control es la actividad de seguimiento a las actividades desarrolladas en las instituciones con el propósito de evitar y/o corregir oportunamente cualquier cambio ejecutado fuera de los objetivos institucionales. El control se ejerce sobre lo planificado frente a lo ejecutado mediante la comparación regular y sistemática en proporción a los objetivos, parte del control es el establecimiento de estándares que es la guía para iniciar el control. La medición de resultados, será variable dependiendo de las entidades. La corrección, que permite la implementación de recomendaciones en el caso de la desviación de los objetivos. El establecimiento de medidas correctivas da lugar a la 


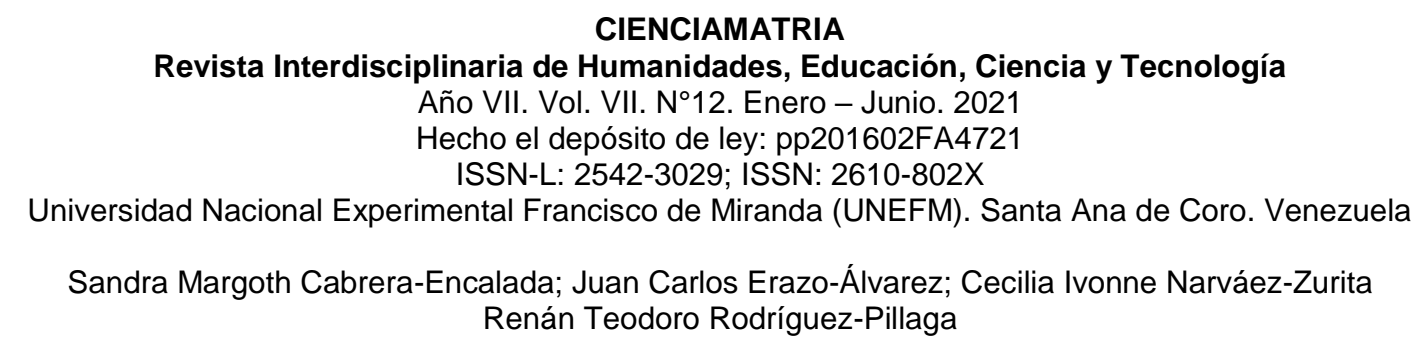

retroalimentación; siendo la relación más estrecha entre planificación y control (Carrasco, 2001).

El control interno, es un medio para la consecución de las metas institucionales, por tanto, es un proceso en el que intervienen todos los funcionarios desde la dirección hasta los servidores públicos en todos sus niveles, por lo que es importante que conozcan la normativa legal, sus componentes, así como la importancia de su implementación y operatividad en el ámbito de sus competencias (Pungitore, 2010).

El ejercicio del control interno cumple con principios de igualdad, eficiencia, economía, celeridad e imparcialidad, por tal motivo su ejecución es esencial para llevar adelante todas las funciones de los cargos existentes en la organización en especial para los cargos directivos, lo cual se verá reflejado en las políticas aprobadas por los mandos de dirección y mandos medios de los organismos estatales a cumplirse en todo el sistema administrativo, mediante la elaboración y aplicación de técnicas de dirección, verificación y evaluación (Guerra, 2015).

Un sistema de control interno eficiente reduce la probabilidad de incumplimiento de los objetivos institucionales, sin embargo, no puede cambiar una administración deficiente por una eficiente considerando que los factores externos fuera de control de una institución, como lo es tema político impactará de distintas maneras en la consecución de objetivos (Murillo-Apolo, et al., 2019).

Según las normas de control interno para las entidades, organismos del sector público y de las personas jurídicas de derecho privado que dispongan de recursos públicos, se establecen como responsables del control interno a todos los servidores públicos dentro del ámbito de sus funciones amparados en los instrumentos legales y técnicos vigentes, quienes contarán con las competencias profesionales para el desarrollo de las funciones para las cuales son contratados a fin de lograr los objetivos institucionales (Reyes, et al., 2020). 


\section{CIENCIAMATRIA \\ Revista Interdisciplinaria de Humanidades, Educación, Ciencia y Tecnología \\ Año VII. Vol. VII. N¹2. Enero - Junio. 2021 \\ Hecho el depósito de ley: pp201602FA4721 \\ ISSN-L: 2542-3029; ISSN: 2610-802X \\ Universidad Nacional Experimental Francisco de Miranda (UNEFM). Santa Ana de Coro. Venezuela \\ Sandra Margoth Cabrera-Encalada; Juan Carlos Erazo-Álvarez; Cecilia Ivonne Narváez-Zurita Renán Teodoro Rodríguez-Pillaga}

Todas las instituciones del sector público contarán con un servidor o unidad responsable de la administración de bienes dependiendo de la estructura de la entidad, siendo los responsables de fomentar los procesos para un efectivo control de los bienes muebles e inmuebles y tecnológicos, en el caso de los bienes de larga duración serán utilizados de manera exclusiva para las actividades propias de la institución, en ningún caso para fines particulares y/o políticos, el custodio final mediante acta entrega - recepción para este tipo de bienes será el responsable de su buen uso y mantenimiento del bien a su cargo, en caso de daños estos serán reportados a la unidad encargada.

Los vehículos de las entidades públicas están destinados únicamente para el desarrollo de las gestiones institucionales durante la jornada laboral, en ningún caso se utilizarán para fines personales, ni en actividades electorales y políticas. Con el objetivo de controlar este tipo de bienes, las unidades responsables llevarán un registro diario de la movilización de cada vehículo, denominado control vehicular, cuando por necesidad institucional los automotores deban ser utilizados fuera de los días y horas laborables, requieren la autorización de la autoridad competente, con la respectiva orden de movilización de acuerdo a la normativa vigente.

Los servidores y/o empleados que tienen a su cargo vehículos oficiales, deberán guardarlos en los parqueaderos designados por la institución, siendo responsabilidad de la máxima autoridad de cada institución disponer que se cumpla con lo establecido en el Reglamento General Sustitutivo para el Manejo y Administración de Bienes del Sector Público y demás disposiciones, emitidas por la Contraloría General del Estado, relacionadas con los bienes públicos.

Las unidades administrativas de cada entidad programarán los mantenimientos preventivos y correctivos debidamente justificados de los bienes de larga duración, como son los equipos tecnológicos con el fin de que las actividades operativas no sean interrumpidas, para ello las diferentes dependencias de las entidades realizarán el requerimiento correspondiente. 
Serán las máximas autoridades y los directivos quienes valoren periódicamente el sistema de control interno, a fin de identificar las debilidades del control implantado en caso de existir y de esta manera adaptarlo a las circunstancias. Las unidades de auditoría interna realizarán exámenes periódicos luego de lo cual emitirán las disposiciones, recomendaciones y observaciones siendo responsabilidad de la unidad a la cual están dirigidas el efectuar las acciones correspondientes dentro del tiempo establecido, por cuanto la implementación es de carácter obligatorio (Celi de la Torre, 2019).

\section{La Gestión Administrativa en las Unidades Desconcentradas del Ejecutivo del Siglo $\mathbf{X X I}$}

La administración es la acción de administrar para la obtención de los resultados esperados dentro de una institución mediante la utilización adecuada de los recursos disponibles tanto materiales como económicos, es decir es sistematizar las actividades en base a los recursos disponibles para obtener los objetivos planteados (Leonard, 2001). Operativamente la administración consiste en prever, organizar, mandar, coordinar y controlar, a más de ser el arte de encaminar en beneficio de la institución las competencias profesionales de los servidores (Angradoña, 2012).

La palabra administración deriva del latín ad (dirección, tendencia) y minister (subordinación u obediencia), es decir realizar actividades bajo la dirección de un tercero, es el proceso de planificar, organizar, dirigir y controlar el buen uso de los recursos en pro de conseguir los recursos institucionales (Chiavenato, 2004). Desde finales del siglo XIX se define a la gestión administrativa en términos de funciones que deben llevar a cabo los directivos de las entidades, por ejemplo: el planeamiento, la organización, la dirección y el control, con el fin de llegar a los objetivos planteados, optimizando los recursos humanos y financieros (Langrod, 2010).

En el ámbito público la administración financiera se encuentra intrínsecamente ligada a la aplicación de la normativa vigente, tomando como base los objetivos de las políticas 
públicas, generando informes adecuados y oportunos para la toma de decisiones (Guerrero, 2008). Administrar significa planificar, organizar, dirigir y controlar los actos administrativos desarrollados en las entidades públicas, actividades que forman parte integrante de la gestión administrativa presentes en todas las áreas de las instituciones, es decir, que todos los servidores desempeñan actividades de planeación, organización, dirección y control, como actividades administrativas esenciales. La planeación, consiste en conocer anticipadamente, el camino para la consecución de los objetivos con eficacia, es decir encaminar todas las acciones para llegar a las metas planteadas con anterioridad (Reyes, 2012).

Organizar es tomar decisiones con el propósito de llegar a cumplir los objetivos institucionales que comprende la delegación de funciones y actividades en el ámbito de las competencias de cada servidor público quien rendirá cuentas al superior correspondiente y a las entidades relacionadas. Los elementos de la organización son: segmentación de las actividades asignadas, coordinación y dirección (Chacon, 2002).

Dirección es el proceso para dirigir e influir en el desarrollo de las actividades de los funcionarios de las entidades, en relación a sus funciones. La dirección llega al fondo de las relaciones de los mandos medios con cada uno de los funcionarios que conformar el equipo (Charry-Rodríguez, 2013).

En el ámbito público, los funcionarios tienen como objetivo principal el servicio tanto al usuario interno como externo con una administración responsable de los recursos públicos, la alta dirección y los funcionarios de todos los niveles están involucrados en el proceso de control para resolver los posibles riesgos y proporcionar seguridad razonable en el logro de la misión institucional (Angradoña, 2012).

Dentro de las etapas del proceso administrativo podemos mencionar, la fase mecánica o estructural que comprende la planeación y organización es decir los escenarios futuros a los cuales se dirige la institución, determinando las estructuras, procesos, funciones y responsabilidades a cada servidor público de la entidad. La fase dinámica u operativa 


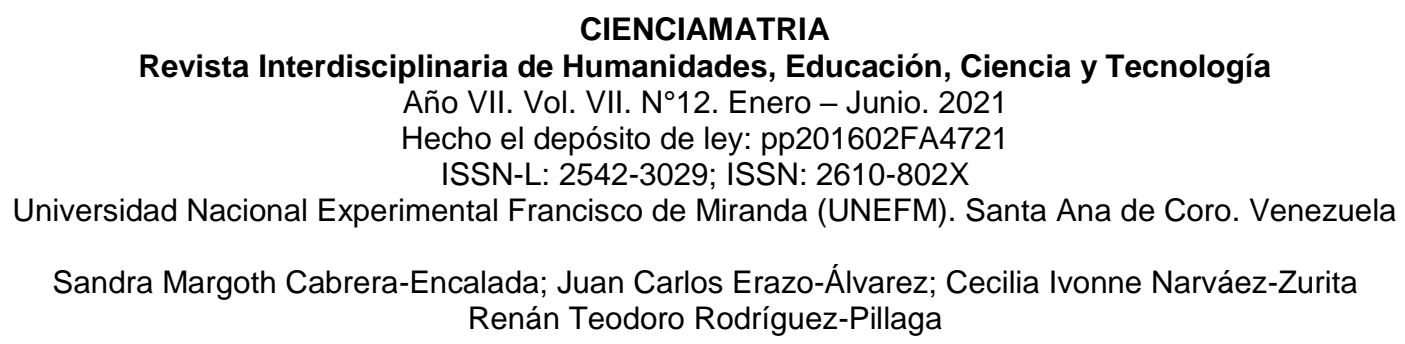

que comprende la integración, dirección o ejecución y el control, en donde se seleccionan medios para ejecutar las actividades, ejerciendo liderazgo, estableciendo modelos de evaluación de los rendimientos obtenidos (Münch, 2010).

La gestión administrativa contiene componentes importantes y un marco legal vigente que el nivel jerárquico superior debe aplicar en el ámbito de sus competencias, así como los demás funcionarios públicos de las entidades que pueden apoyarse en el asesor jurídico, por cuanto los directivos fundamentan sus decisiones en el derecho público.

En la actualidad se puede apreciar como varios negocios han cerrado sus puertas, siendo la mayor deficiencia la falta de administración eficaz de los recursos disponibles, en el sector público que brinda servicios a la población la problemática es diferente debido al exceso de gasto público por la falta de optimización de los recursos tanto económicos como humanos, en donde se aplicará distinta normativa legal como LOSEP y/o código de trabajo dependiendo de la modalidad de vinculación a la institución (OrmazaRodríguez, et al., 2020).

\section{MÉTODO}

El alcance metodológico de la investigación se basó en un tipo descriptiva con diseño de campo no experimental transversal, recopilándose información en único momento a través de encuesta online y cuestionario de alternativas de respuestas combinadas en dicotómicas y escalamiento de Likert, configurado en 11 ítems, siendo validado por juicio de expertos y cálculo de fiabilidad Kuder-Richardson 20 para las preguntas dicotómicas y Alfa de Cronbach para el escalamiento Likert, obteniéndose resultados de 0,78 y 0,81 que permitieron aplicar el instrumento de forma confiable, el cual fue aplicado a una muestra poblacional de 40 servidores públicos que laboran en las unidades desconcentradas del ejecutivo y que desempeñan funciones en el área administrativa de la ciudad de Cuenca - Ecuador, una vez obtenidos los resultados, se procesaron en función de la estadística descriptiva con apoyo de Microsoft Excel versión 2019. 


\section{CIENCIAMATRIA}

Revista Interdisciplinaria de Humanidades, Educación, Ciencia y Tecnología

Año VII. Vol. VII. N¹2. Enero - Junio. 2021

Hecho el depósito de ley: pp201602FA4721

ISSN-L: 2542-3029; ISSN: 2610-802X

Universidad Nacional Experimental Francisco de Miranda (UNEFM). Santa Ana de Coro. Venezuela

Sandra Margoth Cabrera-Encalada; Juan Carlos Erazo-Álvarez; Cecilia Ivonne Narváez-Zurita

Renán Teodoro Rodríguez-Pillaga

\section{RESULTADOS}

La presente investigación tiene como fuente de información los resultados obtenidos en la encuesta, la misma que estuvo dirigida a los servidores públicos que laboran en las unidades desconcentradas del ejecutivo y que desempeñan funciones en el área administrativa, de acuerdo al siguiente detalle:

\section{Dimensión bienes de control administrativo}

Para los funcionarios públicos del área administrativa de las entidades desconcentradas, el $100 \%$ considera que es necesario que los bienes se encuentren regularizados al interior de las instituciones, 97,50\% manifiesta que la unidad administrativa es la encargada entre otras actividades de la recepción, registro, custodia, control, administración, egreso o baja de los bienes o inventarios, $90 \%$ estima que son responsables todos los servidores de la institución donde laboran de la custodia, cuidado y uso de los bienes institucionales.

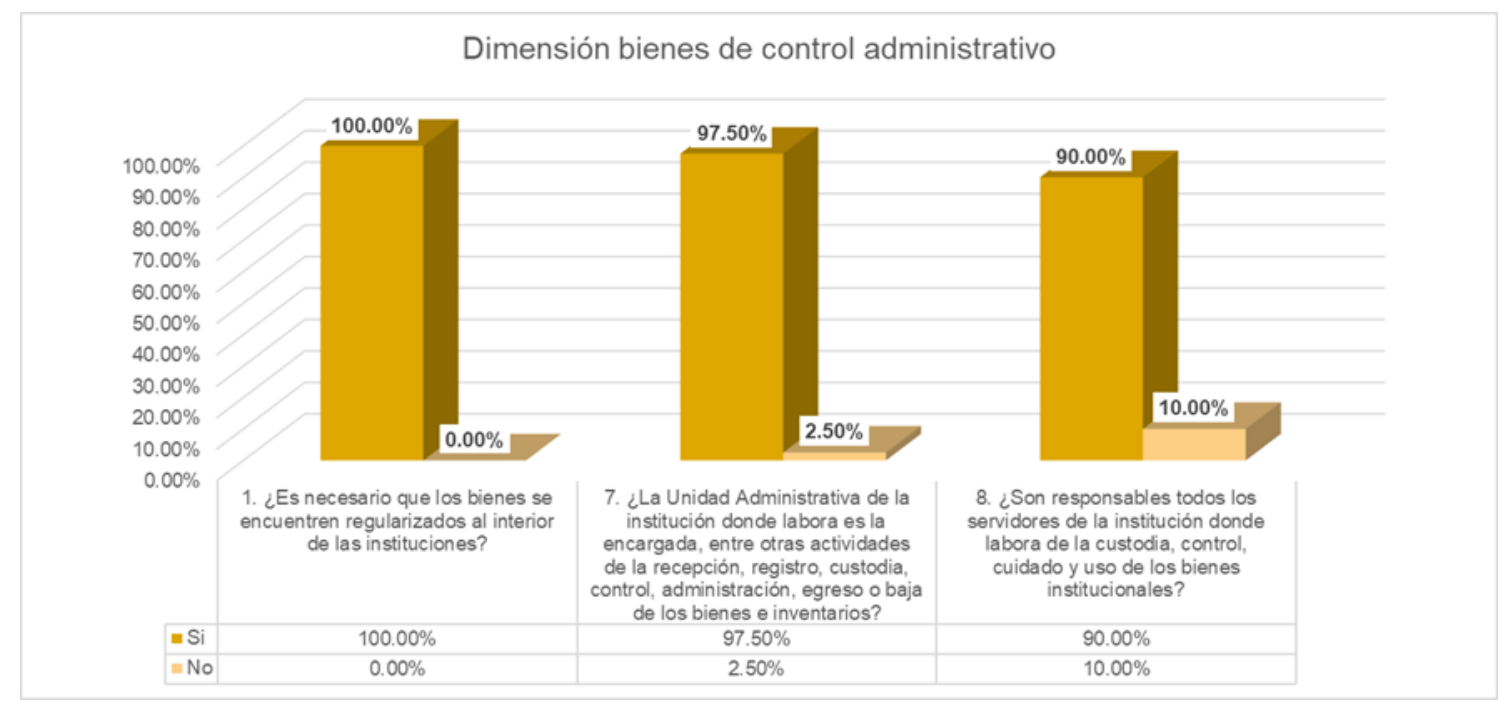

Figura 1. Dimensión bienes de control administrativo.

Fuente: Encuestas. 


\section{CIENCIAMATRIA}

Revista Interdisciplinaria de Humanidades, Educación, Ciencia y Tecnología

Año VII. Vol. VII. N¹2. Enero - Junio. 2021

Hecho el depósito de ley: pp201602FA4721

ISSN-L: 2542-3029; ISSN: 2610-802X

Universidad Nacional Experimental Francisco de Miranda (UNEFM). Santa Ana de Coro. Venezuela

Sandra Margoth Cabrera-Encalada; Juan Carlos Erazo-Álvarez; Cecilia Ivonne Narváez-Zurita

Renán Teodoro Rodríguez-Pillaga

\section{Dimensión bienes de larga duración}

En cuanto a esta dimensión $67,50 \%$ de los encuestados, manifiesta que se deben utilizar los bienes públicos en casos considerados de emergencia, el $42,50 \%$ de los servidores consultados está de acuerdo en que se reencauche los neumáticos de los vehículos púbicos, 92,50\% considera que los vehículos institucionales deben ser conducidos únicamente por choferes profesionales, $92,50 \%$ de los encuestados indica que la institución donde prestan sus servicios emite ordenes de movilización para los vehículos institucionales.

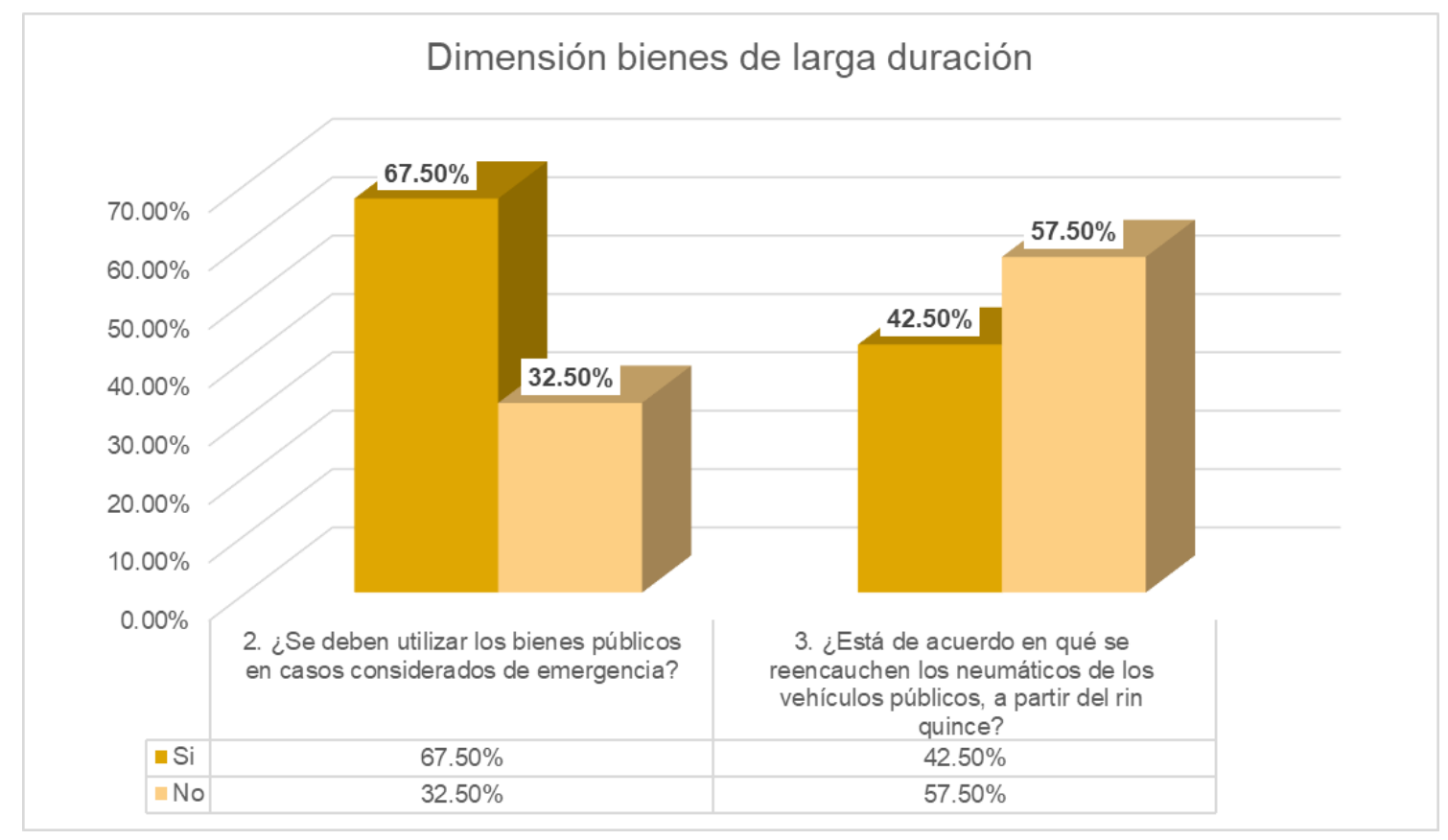

Figura 2. Dimensión bienes de larga duración.

Fuente: Encuestas. 


\section{CIENCIAMATRIA}

Revista Interdisciplinaria de Humanidades, Educación, Ciencia y Tecnología

Año VII. Vol. VII. N¹2. Enero - Junio. 2021

Hecho el depósito de ley: pp201602FA4721 ISSN-L: 2542-3029; ISSN: 2610-802X

Universidad Nacional Experimental Francisco de Miranda (UNEFM). Santa Ana de Coro. Venezuela

Sandra Margoth Cabrera-Encalada; Juan Carlos Erazo-Álvarez; Cecilia Ivonne Narváez-Zurita Renán Teodoro Rodríguez-Pillaga

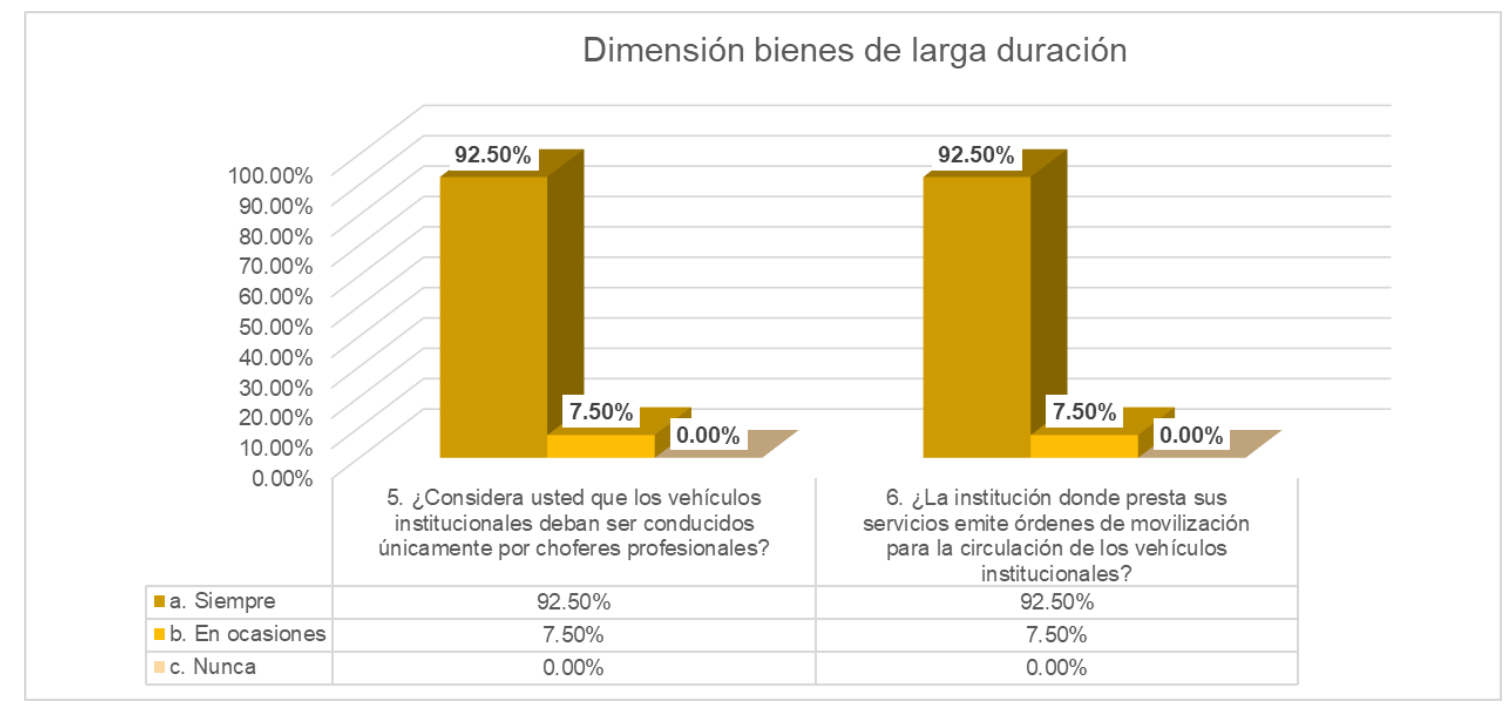

Figura 3. Dimensión bienes de larga duración.

Fuente: Encuestas.

\section{Dimensión competencias profesionales}

Referente a las competencias profesionales, el 100\% considera esencial que las competencias profesionales sean acordes a las funciones y responsabilidades asignadas, $97,50 \%$ está de acuerdo que la máxima autoridad y los servidores responsables del control interno establezcan políticas para proteger y conservar los activos, $80 \%$ indica que la unidad administrativa de la institución donde labora gestiona el mantenimiento preventivo y correctivo de los bienes de larga duración. 


\section{CIENCIAMATRIA}

Revista Interdisciplinaria de Humanidades, Educación, Ciencia y Tecnología

Año VII. Vol. VII. N¹2. Enero - Junio. 2021

Hecho el depósito de ley: pp201602FA4721

ISSN-L: 2542-3029; ISSN: 2610-802X

Universidad Nacional Experimental Francisco de Miranda (UNEFM). Santa Ana de Coro. Venezuela

Sandra Margoth Cabrera-Encalada; Juan Carlos Erazo-Álvarez; Cecilia Ivonne Narváez-Zurita Renán Teodoro Rodríguez-Pillaga

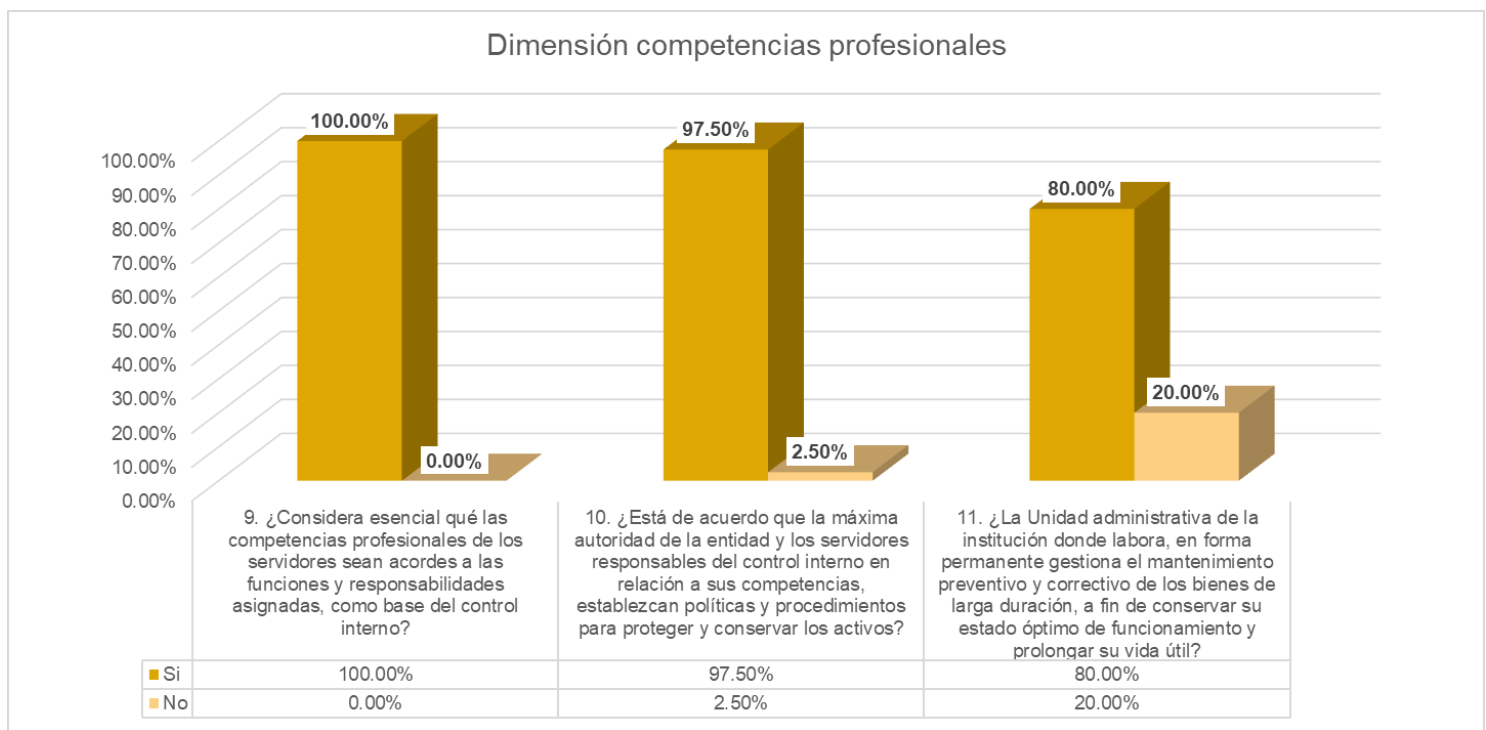

Figura 4. Dimensión competencias profesionales.

Fuente: Encuestas. 


\section{CIENCIAMATRIA}

Revista Interdisciplinaria de Humanidades, Educación, Ciencia y Tecnología

Año VII. Vol. VII. N¹2. Enero - Junio. 2021

Hecho el depósito de ley: pp201602FA4721

ISSN-L: 2542-3029; ISSN: 2610-802X

Universidad Nacional Experimental Francisco de Miranda (UNEFM). Santa Ana de Coro. Venezuela

Sandra Margoth Cabrera-Encalada; Juan Carlos Erazo-Álvarez; Cecilia Ivonne Narváez-Zurita

Renán Teodoro Rodríguez-Pillaga

\section{PROPUESTA}

La presente constituye una propuesta de mejoramiento al procedimiento del control interno vigente en los procesos administrativos de las unidades desconcentradas del poder ejecutivo, la cual persigue minimizar las insuficiencias permitiendo mejorar resultados de la gestión administrativa, optimizando el uso de los recursos públicos.

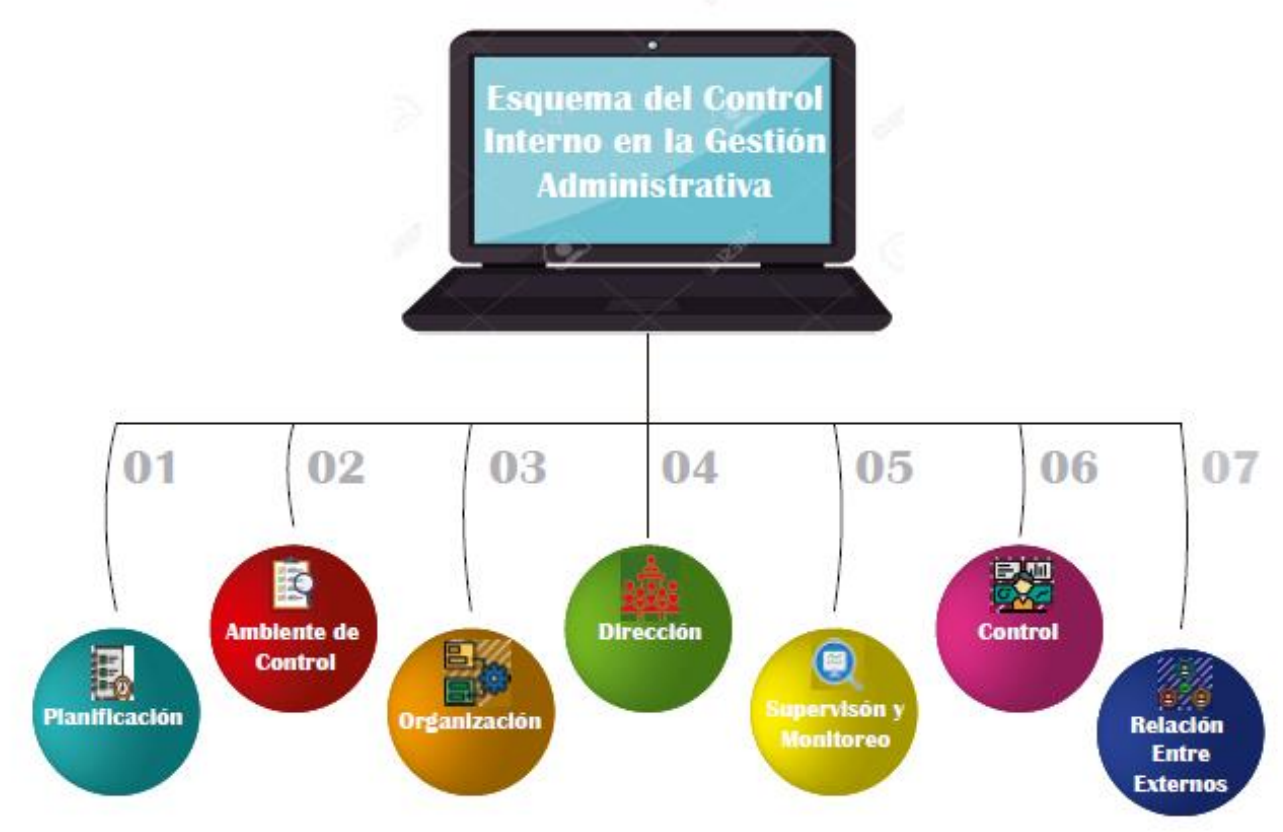

Figura 5. Propuesta del control interno en la gestión administrativa.

A continuación, el desarrollo de la propuesta que cumplirá con el objetivo de minimizar las deficiencias mejorando los resultados de la gestión administrativa, optimizando el uso de los recursos públicos. 


\section{CIENCIAMATRIA}

Revista Interdisciplinaria de Humanidades, Educación, Ciencia y Tecnología

Año VII. Vol. VII. N¹2. Enero - Junio. 2021

Hecho el depósito de ley: pp201602FA4721

ISSN-L: 2542-3029; ISSN: 2610-802X

Universidad Nacional Experimental Francisco de Miranda (UNEFM). Santa Ana de Coro. Venezuela

Sandra Margoth Cabrera-Encalada; Juan Carlos Erazo-Álvarez; Cecilia Ivonne Narváez-Zurita

Renán Teodoro Rodríguez-Pillaga

\section{Planificación}

Tabla 1.

La planificación en la gestión administrativa.

\begin{tabular}{|c|c|c|c|}
\hline $\begin{array}{c}\text { Descripción de la } \\
\text { Unidad }\end{array}$ & Objetivo de la Unidad & Acciones/Estrategias & $\begin{array}{c}\text { Meta } \\
\text { cuantificable }\end{array}$ \\
\hline $\begin{array}{l}\text { Direcciones } \\
\text { Regionales }\end{array}$ & $\begin{array}{l}\text { Planificar, coordinar y } \\
\text { supervisar el funcionamiento y } \\
\text { organización de los servicios } \\
\text { de la entidad. }\end{array}$ & $\begin{array}{l}\text { Elaborar el Plan Operativo } \\
\text { Regional. } \\
\text { Coordinar la gestión administrativa } \\
\text { - financiera Regional. } \\
\text { Supervisar el seguimiento y control } \\
\text { de la regional. }\end{array}$ & $\begin{array}{c}\text { Verificable } \\
\text { semestralmente }\end{array}$ \\
\hline $\begin{array}{l}\text { Unidades } \\
\text { Administrativas de } \\
\text { Atención al Usuario }\end{array}$ & $\begin{array}{l}\text { Garantizar que los servicios de } \\
\text { atención a los usuarios } \\
\text { externos cumplan los } \\
\text { estándares de calidad } \\
\text { establecidos en cada } \\
\text { institución en beneficio de la } \\
\text { ciudadanía. }\end{array}$ & $\begin{array}{l}\text { Orientar al servicio a los servidores } \\
\text { públicos. } \\
\text { Evaluar el nivel de satisfacción del } \\
\text { usuario externo. } \\
\text { Informar sobre la gestión realizada. } \\
\text { Crear nuevos puntos de atención al } \\
\text { usuario. } \\
\text { Constatar el número de usuarios } \\
\text { que solventaron sus } \\
\text { requerimientos en la Regional. } \\
\text { Evaluar las actividades de control } \\
\text { implementadas para brindar } \\
\text { servicio de calidad al usuario } \\
\text { externo. }\end{array}$ & $\begin{array}{c}\text { Verificable } \\
\text { mensualmente }\end{array}$ \\
\hline
\end{tabular}




\section{CIENCIAMATRIA}

Revista Interdisciplinaria de Humanidades, Educación, Ciencia y Tecnología

Año VII. Vol. VII. N¹2. Enero - Junio. 2021

Hecho el depósito de ley: pp201602FA4721

ISSN-L: 2542-3029; ISSN: 2610-802X

Universidad Nacional Experimental Francisco de Miranda (UNEFM). Santa Ana de Coro. Venezuela

Sandra Margoth Cabrera-Encalada; Juan Carlos Erazo-Álvarez; Cecilia Ivonne Narváez-Zurita Renán Teodoro Rodríguez-Pillaga

\section{Controlar el nivel de ejecución presupuestaria a nivel regional periódicamente.}

Fuente: Defensoría Pública (2018).

\section{Ambiente de Control}

Corresponde al comportamiento de toda la estructura organizacional de las entidades desconcentradas que se relaciona directamente con los procedimientos institucionales.

\section{Tabla 2.}

El ambiente de control en la gestión administrativa.

Objetivo: Verificar los procesos que forman parte del ambiente de control de las unidades desconcentradas del ejecutivo, en relación a las actividades de cada una de las dependencias con el propósito de dar cumplimiento de la misión institucional.

\begin{tabular}{|c|c|c|c|c|c|c|c|}
\hline $\begin{array}{c}\text { Procedimiento } \\
\text { Institucional a } \\
\text { Observarse }\end{array}$ & 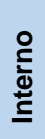 & Causas & Consecuencias & $\begin{array}{l}\text { Nivel de } \\
\text { Riesgo }\end{array}$ & $\begin{array}{l}\text { Controles } \\
\text { Existentes }\end{array}$ & $\begin{array}{l}\text { Acciones a } \\
\text { Ejecutarse }\end{array}$ & $\begin{array}{c}\text { Unidad } \\
\text { Responsable }\end{array}$ \\
\hline $\begin{array}{lr}\text { Incumplimiento } & \text { al } \\
\text { proceso } & \text { de } \\
\text { seguimiento } & \text { y } \\
\text { evaluación } & \text { del } \\
\text { avance de } & \text { la } \\
\text { gestión } & \\
\text { institucional. } & \end{array}$ & $X$ & $\begin{array}{l}\text { No suministro de } \\
\text { información a } \\
\text { tiempo por parte de } \\
\text { las dependencias. } \\
\text { Falta de personal } \\
\text { que cumpla con el } \\
\text { perfil del puesto. } \\
\text { Falta de planeación } \\
\text { en las actividades } \\
\text { institucionales }\end{array}$ & $\begin{array}{l}\text { No aplicación de } \\
\text { correctivos } \\
\text { oportunamente } \\
\text { en base a } \\
\text { recomendaciones } \\
\text { Retraso en las } \\
\text { actividades } \\
\text { asignadas. } \\
\text { Sanciones. }\end{array}$ & Importante & $\begin{array}{l}\text { Matriz de control } \\
\text { a la gestión } \\
\text { institucional. } \\
\\
\text { Cronograma de } \\
\text { actividades a } \\
\text { desarrollarse. }\end{array}$ & $\begin{array}{l}\text { Ampliar plazos } \\
\text { para la } \\
\text { presentación de la } \\
\text { matriz. } \\
\text { Reuniones de } \\
\text { seguimiento con } \\
\text { su respectiva } \\
\text { acta. }\end{array}$ & $\begin{array}{l}\text { Unidad } \\
\text { Administrativa - } \\
\text { Financiera }\end{array}$ \\
\hline
\end{tabular}


CIENCIAMATRIA

Revista Interdisciplinaria de Humanidades, Educación, Ciencia y Tecnología

Año VII. Vol. VII. N¹2. Enero - Junio. 2021

Hecho el depósito de ley: pp201602FA4721

ISSN-L: 2542-3029; ISSN: 2610-802X

Universidad Nacional Experimental Francisco de Miranda (UNEFM). Santa Ana de Coro. Venezuela

Sandra Margoth Cabrera-Encalada; Juan Carlos Erazo-Álvarez; Cecilia Ivonne Narváez-Zurita Renán Teodoro Rodríguez-Pillaga

\begin{tabular}{|c|c|c|c|c|c|c|c|}
\hline $\begin{array}{l}\text { Falta de } \\
\text { seguimiento a la } \\
\text { presentación } \\
\text { oportuna de } \\
\text { informes por parte } \\
\text { de } \\
\text { dependencias } \\
\text { internas de control } \\
\text { ubicadas en planta } \\
\text { central de cada } \\
\text { entidad } \\
\text { desconcentrada. }\end{array}$ & $X$ & $\begin{array}{l}\text { Falta de planeación } \\
\text { por } \\
\text { desconocimiento de } \\
\text { la normativa } \\
\text { vigente. }\end{array}$ & $\begin{array}{l}\text { Sanciones } \\
\text { disciplinarias. } \\
\text { Pecuniarias }\end{array}$ & Moderado & $\begin{array}{ll}\text { Matriz } & \text { de } \\
\text { Informes. } & \end{array}$ & $\begin{array}{l}\text { Prevenir } \\
\text { Verificar fechas } \\
\text { de presentación. }\end{array}$ & $\begin{array}{l}\text { Unidad } \\
\text { Administrativa - } \\
\text { Financiera }\end{array}$ \\
\hline $\begin{array}{l}\text { Falta de } \\
\text { seguimiento } \\
\text { control al avance } \\
\text { del plan institucional } \\
\text { planteado. }\end{array}$ & $X$ & $\begin{array}{l}\text { No cumplimiento del } \\
\text { cronograma } \\
\text { planteado por parte } \\
\text { de la dependencia } \\
\text { encargada de } \\
\text { planificación. }\end{array}$ & $\begin{array}{l}\text { No cumplimiento } \\
\text { de los objetivos } \\
\text { de la unidad de } \\
\text { control interno }\end{array}$ & Tolerable & $\begin{array}{l}\text { Cronograma de } \\
\text { visitas a las } \\
\text { delegaciones que } \\
\text { forman parte de } \\
\text { las unidades } \\
\text { desconcentradas. }\end{array}$ & $\begin{array}{l}\text { Monitorear el } \\
\text { avance del plan } \\
\text { institucional por } \\
\text { dependencias. }\end{array}$ & $\begin{array}{l}\text { Unidad } \\
\text { Administrativa - } \\
\text { Financiera }\end{array}$ \\
\hline $\begin{array}{l}\text { Inexistencia de la } \\
\text { cultura del } \\
\text { autocontrol en lo } \\
\text { referente al uso y } \\
\text { cuidado de los } \\
\text { bienes } \\
\text { institucionales }\end{array}$ & $X$ & $\begin{array}{l}\text { No existen } \\
\text { mecanismos que } \\
\text { fomenten la cultura } \\
\text { del autocontrol. } \\
\text { Existe rechazo a la } \\
\text { función que debe } \\
\text { cumplir } \\
\text { dependencia } \\
\text { encargada } \\
\text { control interno. }\end{array}$ & $\begin{array}{l}\text { Ineficiencia en la } \\
\text { aplicación de } \\
\text { procedimientos. } \\
\text { No aplicación de } \\
\text { correctivos. }\end{array}$ & Importante & $\begin{array}{l}\text { Planes de } \\
\text { mejoramiento. } \\
\text { Seguimiento a las } \\
\text { inconsistencias. } \\
\text { Controles } \\
\text { disciplinarios. }\end{array}$ & $\begin{array}{l}\text { Realizar } \\
\text { capacitaciones } \\
\text { sobre el } \\
\text { reglamento uso } \\
\text { de bienes } \\
\text { públicos. }\end{array}$ & $\begin{array}{l}\text { Unidad } \\
\text { Administrativa - } \\
\text { Financiera }\end{array}$ \\
\hline
\end{tabular}

Fuente: Elaboración propia. 
CIENCIAMATRIA

Revista Interdisciplinaria de Humanidades, Educación, Ciencia y Tecnología

Año VII. Vol. VII. N¹2. Enero - Junio. 2021

Hecho el depósito de ley: pp201602FA4721

ISSN-L: 2542-3029; ISSN: 2610-802X

Universidad Nacional Experimental Francisco de Miranda (UNEFM). Santa Ana de Coro. Venezuela

Sandra Margoth Cabrera-Encalada; Juan Carlos Erazo-Álvarez; Cecilia Ivonne Narváez-Zurita

Renán Teodoro Rodríguez-Pillaga

\section{Organización y dirección}

Consiste en la determinación de las estructuras, procesos, sistemas, métodos y procedimientos tendientes a la optimización de los recursos humanos y financieros, mediante una dirección adecuada.

Tabla 3.

Organización de las actividades administrativas de las unidades desconcentradas.

\begin{tabular}{|c|c|c|c|c|c|c|c|c|c|c|c|c|c|c|c|}
\hline ORD. & $\begin{array}{c}\text { DESCRIPCION DE LA } \\
\text { ACTIVIDAD }\end{array}$ & $\begin{array}{l}\text { DEPENDENCIA } \\
\text { ENCARGADA }\end{array}$ & Ene & Feb & Mar & Abr & May & Jun & Jul & Ago & Sep & Oct & Nov & Dic & Frecuencia \\
\hline 1 & $\begin{array}{l}\text { Informar sobre el avance anual } \\
\text { de las actividades realizadas por } \\
\text { la unidad encargada del control } \\
\text { interno }\end{array}$ & $\begin{array}{c}\text { Unidad de } \\
\text { Control Interno }\end{array}$ & & & & & & & & & & & & & Anual \\
\hline 2 & $\begin{array}{l}\text { Informar sobre los resultados de } \\
\text { la evaluación de la gestión } \\
\text { administrativa del período } \\
\text { anterior }\end{array}$ & $\begin{array}{c}\text { Unidad } \\
\text { Administrativa }\end{array}$ & & & & & & & & & & & & & Anual \\
\hline 3 & Rendición de cuentas & $\begin{array}{l}\text { Dirección } \\
\text { Regional }\end{array}$ & & & & & & & & & & & & & Anual \\
\hline 4 & $\begin{array}{l}\text { Plan de acción: objetivos, } \\
\text { estrategias, proyectos, metas, } \\
\text { responsables, plan general de } \\
\text { adquisición }\end{array}$ & $\begin{array}{l}\text { Dirección } \\
\text { Regional }\end{array}$ & & & & & & & & & & & & & Anual \\
\hline 5 & $\begin{array}{l}\text { Informe semestral de ejecución } \\
\text { presupuestaria de acuerdo al a } \\
\text { normativa vigente }\end{array}$ & $\begin{array}{c}\text { Unidad } \\
\text { Financiera }\end{array}$ & & & & & & & & & & & & & Semestral \\
\hline 6 & $\begin{array}{l}\text { Arquear y reponer las cajas } \\
\text { chicas administrativas y de } \\
\text { bienes }\end{array}$ & $\begin{array}{c}\text { Unidad } \\
\text { Financiera }\end{array}$ & & & & & & & & & & & & & Semestral \\
\hline 7 & $\begin{array}{l}\text { Colaborar con la unidad de } \\
\text { control interno - auditoría interna } \\
\text { en el examen a los proceso de } \\
\text { contratación pública }\end{array}$ & $\begin{array}{c}\text { Unidad } \\
\text { Administrativa - } \\
\text { Unidad } \\
\text { Financiera }\end{array}$ & & & & & & & & & & & & & Semestral \\
\hline 8 & $\begin{array}{llr}\text { Constatar } & \text { los } & \text { bienes } \\
\text { institucionales } & \text { tales como } \\
\text { tecnológicos, } & \text { muebles } \quad \text { y } \\
\text { vehículos } & & \end{array}$ & $\begin{array}{c}\text { Unidad } \\
\text { Administrativa }\end{array}$ & & & & & & & & & & & & & Semestral \\
\hline 9 & $\begin{array}{l}\text { Publicar el plan anual de } \\
\text { contratación pública (PAC) }\end{array}$ & $\begin{array}{c}\text { Unidad } \\
\text { Administrativa }\end{array}$ & & & & & & & & & & & & & Anual \\
\hline
\end{tabular}


CIENCIAMATRIA

Revista Interdisciplinaria de Humanidades, Educación, Ciencia y Tecnología

Año VII. Vol. VII. N¹2. Enero - Junio. 2021

Hecho el depósito de ley: pp201602FA4721

ISSN-L: 2542-3029; ISSN: 2610-802X

Universidad Nacional Experimental Francisco de Miranda (UNEFM). Santa Ana de Coro. Venezuela

Sandra Margoth Cabrera-Encalada; Juan Carlos Erazo-Álvarez; Cecilia Ivonne Narváez-Zurita

Renán Teodoro Rodríguez-Pillaga

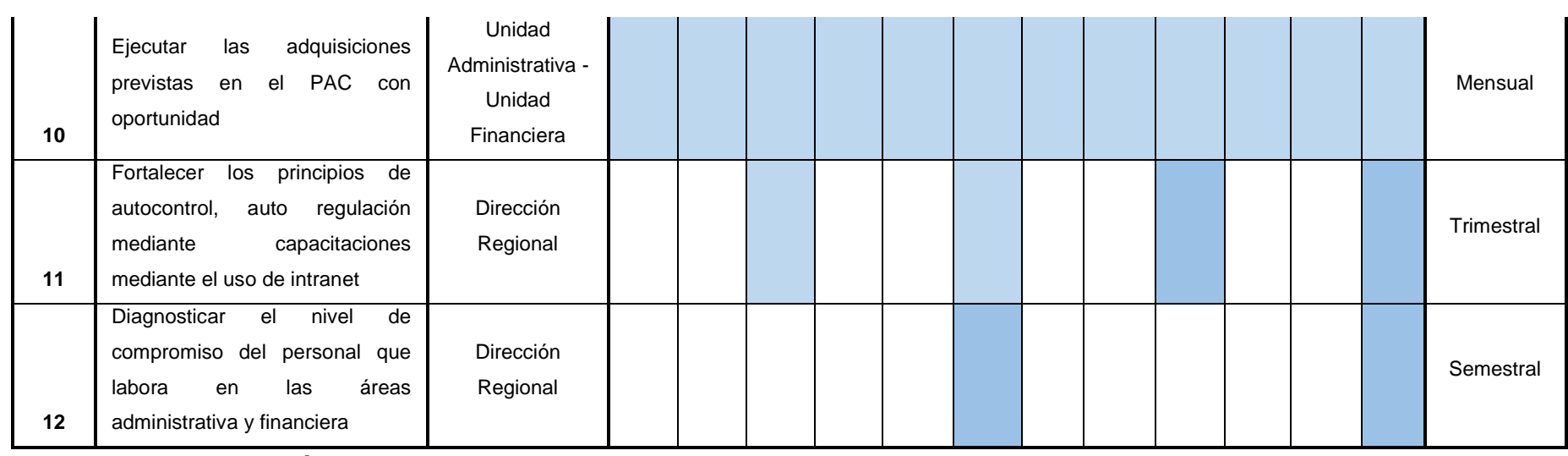

Fuente: Elaboración propia.

\section{Supervisión y monitoreo}

Parte de la propuesta es elaborar un cuestionario para medir el nivel de cumplimiento y control interno en las dependencias administrativas.

Tabla 4.

Cuestionario de Control Interno - Supervisión y Monitoreo.

\begin{tabular}{|c|c|c|c|c|c|}
\hline \multicolumn{6}{|c|}{$\begin{array}{l}\text { CUESTIONARIO DE CONTROL INTERNO } \\
\end{array}$} \\
\hline \multicolumn{6}{|c|}{ SUPERVISION Y MONITOREO } \\
\hline \multirow[b]{2}{*}{ Nro. } & \multirow[b]{2}{*}{ Preguntas } & \multicolumn{4}{|c|}{ Respuestas } \\
\hline & & Sí & No & $\begin{array}{c}\text { En } \\
\text { proceso }\end{array}$ & N/A \\
\hline 1 & ¿Se realiza control previo al resultado de sus actividades? & & & & \\
\hline 2 & $\begin{array}{l}\text { ¿La unidad encargada del control tiene acceso total a la } \\
\text { información de la entidad, cuando estime pertinente? }\end{array}$ & & & & \\
\hline 3 & $\begin{array}{l}\text { ¿Son requisitos importantes en la selección de personal, la } \\
\text { competencia personal y profesional? }\end{array}$ & & & & \\
\hline 4 & $\begin{array}{l}\text { ¿Los informes presentados por la unidad de control evidencian el } \\
\text { cumplimiento del plan de trabajo? }\end{array}$ & & & & \\
\hline 5 & $\begin{array}{l}\text { ¿El plan de trabajo de la unidad de control incluye la verificación de } \\
\text { la efectividad de los procesos de la entidad? }\end{array}$ & & & & \\
\hline
\end{tabular}


CIENCIAMATRIA

Revista Interdisciplinaria de Humanidades, Educación, Ciencia y Tecnología

Año VII. Vol. VII. N¹2. Enero - Junio. 2021

Hecho el depósito de ley: pp201602FA4721

ISSN-L: 2542-3029; ISSN: 2610-802X

Universidad Nacional Experimental Francisco de Miranda (UNEFM). Santa Ana de Coro. Venezuela

Sandra Margoth Cabrera-Encalada; Juan Carlos Erazo-Álvarez; Cecilia Ivonne Narváez-Zurita

Renán Teodoro Rodríguez-Pillaga

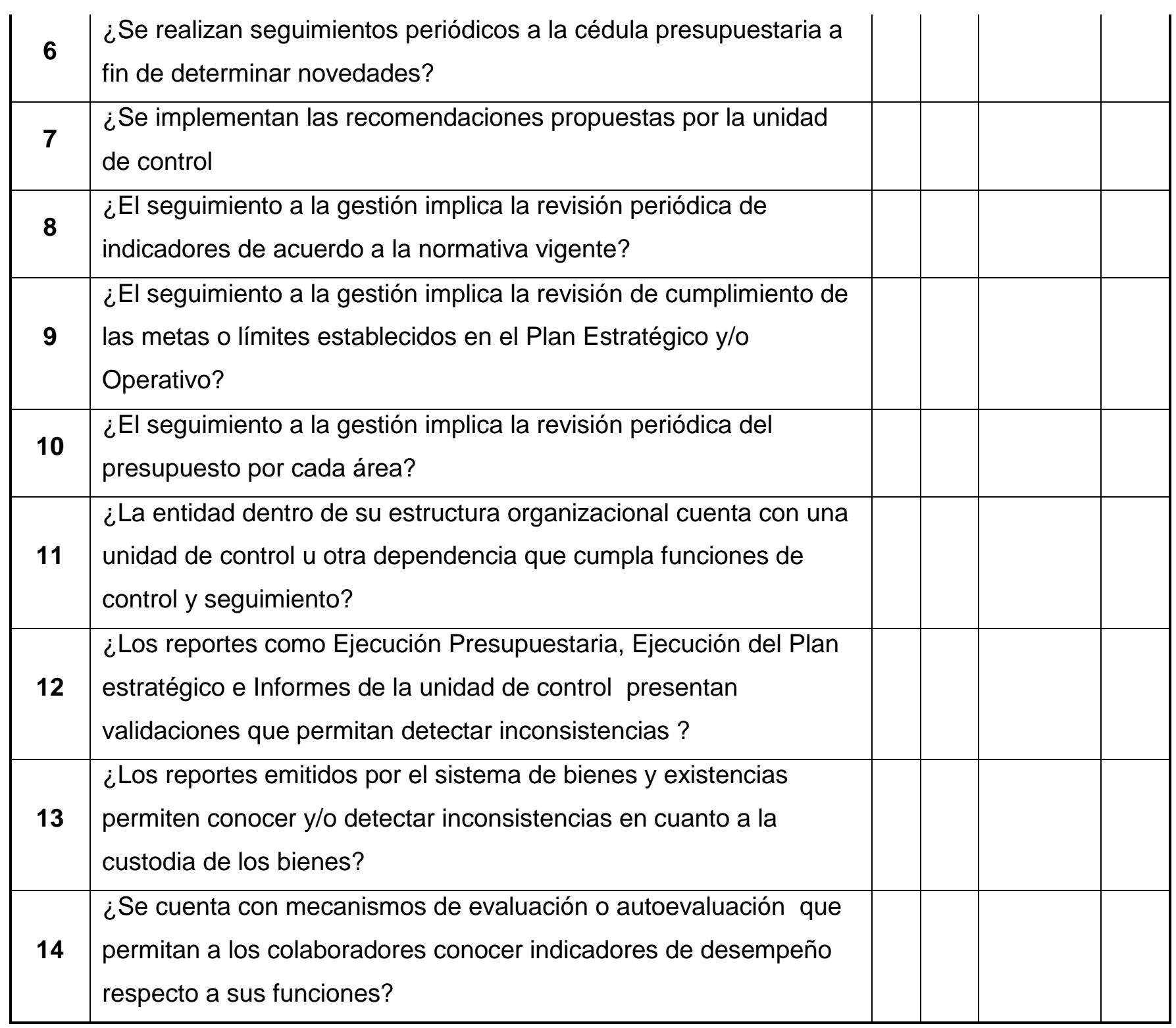

Fuente: Elaboración propia. 
CIENCIAMATRIA

Revista Interdisciplinaria de Humanidades, Educación, Ciencia y Tecnología

Año VII. Vol. VII. N¹2. Enero - Junio. 2021

Hecho el depósito de ley: pp201602FA4721

ISSN-L: 2542-3029; ISSN: 2610-802X

Universidad Nacional Experimental Francisco de Miranda (UNEFM). Santa Ana de Coro. Venezuela

Sandra Margoth Cabrera-Encalada; Juan Carlos Erazo-Álvarez; Cecilia Ivonne Narváez-Zurita

Renán Teodoro Rodríguez-Pillaga

\section{Control}

Para una efectiva gestión administrativa en las unidades desconcentradas del ejecutivo, debe contarse con personal que cuente con las competencias profesionales acordes a las necesidades institucionales para así optimizar el tiempo y servir al usuario interno y externo de manera óptima, el control permitirá eficiencia en los procesos internos y externos lo cual conllevará a un ambiente laboral adecuado.

Tabla 5.

Control en las dependencias de las unidades desconcentradas del ejecutivo.

\begin{tabular}{|l|l|}
\hline \multicolumn{1}{|c|}{$\begin{array}{c}\text { Dependencias de las Unidades } \\
\text { Desconcentradas }\end{array}$} & \multicolumn{1}{|c|}{ Propuesta de Control } \\
\hline Áreas administrativas & $\begin{array}{l}\text { Capacitar constantemente. } \\
\text { Implementar política de competencias } \\
\text { profesionales acorde a las funciones asignadas. } \\
\text { Reducir procesos repetitivos para optimizar } \\
\text { tiempo y recursos. } \\
\text { Asignar los bienes públicos de acuerdo a la } \\
\text { normativa legal vigente. }\end{array}$ \\
\hline Tecnología de la comunicación y & $\begin{array}{l}\text { Capacitar al personal sobre los diversos recursos } \\
\text { tecnológicos con los que cuenta la entidad a fin de } \\
\text { simplificar los diferentes procesos. } \\
\text { Revisar constantemente el estado de los bienes } \\
\text { tecnológicos previo al cambio de custodio final. }\end{array}$ \\
\hline Unidad de Transportes & $\begin{array}{l}\text { Asignar vehículos a las distintas unidades } \\
\text { conforme la disponibilidad. } \\
\text { Verificar periódicamente el estado de los } \\
\text { vehículos (bien de larga duración). }\end{array}$ \\
\hline
\end{tabular}


CIENCIAMATRIA

Revista Interdisciplinaria de Humanidades, Educación, Ciencia y Tecnología

Año VII. Vol. VII. N¹2. Enero - Junio. 2021

Hecho el depósito de ley: pp201602FA4721

ISSN-L: 2542-3029; ISSN: 2610-802X

Universidad Nacional Experimental Francisco de Miranda (UNEFM). Santa Ana de Coro. Venezuela

Sandra Margoth Cabrera-Encalada; Juan Carlos Erazo-Álvarez; Cecilia Ivonne Narváez-Zurita

Renán Teodoro Rodríguez-Pillaga

\begin{tabular}{|l|l|}
\hline & $\begin{array}{l}\text { Cumplir con la normativa legal vigente para el } \\
\text { mantenimiento preventivo y correctivo de los } \\
\text { automotores. }\end{array}$ \\
\hline
\end{tabular}

Fuente: Ormaza-Rodríguez, et al. (2020).

\section{Relación entre externos}

La Constitución de la República, regula la estructura y funciones de los organismos de control, por ello todas las instituciones públicas inclusive las unidades desconcentradas del ejecutivo cumplen con informar al respecto de su gestión de acuerdo al ámbito de sus competencias, de acuerdo al siguiente planteamiento:

Tabla 6. Relación entre externos.

\begin{tabular}{|c|l|c|c|}
\hline Ord. & \multicolumn{1}{|c|}{ Descripción de los Informes } & $\begin{array}{c}\text { Dependencia } \\
\text { Encargada }\end{array}$ & Periodicidad \\
\hline $\mathbf{1}$ & $\begin{array}{l}\text { Rendición de Cuentas de la Gestión } \\
\text { Institucional. }\end{array}$ & $\begin{array}{c}\text { Auditoría Interna de las } \\
\text { Entidades }\end{array}$ & $\begin{array}{c}\text { Anual o en el } \\
\text { momento que lo } \\
\text { requiera }\end{array}$ \\
\hline $\mathbf{2}$ & $\begin{array}{l}\text { Borradores de Informes Finales } \\
\text { efectuados a los distintos procesos } \\
\text { institucionales. }\end{array}$ & $\begin{array}{c}\text { Contraloría General del } \\
\text { Estado }\end{array}$ & Trimestral \\
\hline $\mathbf{3}$ & Obligaciones Tributarias & $\begin{array}{c}\text { Servicio de Rentas } \\
\text { Internas }\end{array}$ & Mensual \\
\hline $\mathbf{4}$ & $\begin{array}{l}\text { Arrendamiento, compra o venta de } \\
\text { bienes inmuebles para utilización de } \\
\text { oficinas de las instituciones públicas }\end{array}$ & $\begin{array}{c}\text { Secretaría Técnica del } \\
\text { Gestión Inmobiliaria del } \\
\text { Sector Público }\end{array}$ & $\begin{array}{c}\text { Semestral o en el } \\
\text { momento que exista } \\
\text { la necesidad }\end{array}$ \\
\hline $\mathbf{5}$ & $\begin{array}{l}\text { Procesos de Seguridad y Vigilancia de } \\
\text { las instituciones }\end{array}$ & $\begin{array}{c}\text { Ministerio de Gobierno } \\
\text { en conjunto con la } \\
\text { Policía Nacional }\end{array}$ & $\begin{array}{c}\text { Semestral o en el } \\
\text { momento que surja } \\
\text { la necesidad }\end{array}$ \\
\hline
\end{tabular}


Universidad Nacional Experimental Francisco de Miranda (UNEFM). Santa Ana de Coro. Venezuela

Sandra Margoth Cabrera-Encalada; Juan Carlos Erazo-Álvarez; Cecilia Ivonne Narváez-Zurita Renán Teodoro Rodríguez-Pillaga

\begin{tabular}{|l|l|l|c|}
$\mathbf{6}$ & $\begin{array}{l}\text { Fondos de Terceros o recursos } \\
\text { provenientes del sector privado que } \\
\text { ingresan al sector público para diversas } \\
\text { asignaciones }\end{array}$ & BAN Ecuador & Mensual \\
\hline $\mathbf{7}$ & $\begin{array}{l}\text { Trámites judiciales en el ámbito de las } \\
\text { competencias }\end{array}$ & Consejo de la Judicatura & $\begin{array}{c}\text { Mensual o el } \\
\text { momento en que } \\
\text { exista la necesidad }\end{array}$ \\
\hline
\end{tabular}

Fuente: Elaboración propia.

\section{CONCLUSIONES}

Luego de efectuada la investigación, se concluye que las competencias laborales son importantes al momento de asignar funciones determinadas al personal, lo que ocasionó que no se cumplieran con oportunidad los objetivos.

A fin de contribuir con la gestión administrativa se propone mejorar el conocimiento del entorno legal vigente en lo referente al uso de los bienes y recursos públicos, que permita lograr los objetivos institucionales mejorando el servicio al usuario interno como externo. Con la aplicación de esta propuesta se mejoró la planificación de las actividades institucionales enfocadas en el conocimiento de la periodicidad con la cual tiene que cumplirse determinadas labores, permitiendo la mejora de la gestión administrativa al interior de la institución y fuera de ella con su relación con las entidades relacionas.

\section{REFERENCIAS CONSULTADAS}

Argandoña, M. (2012). Control Interno y Administración de Riesgo en la Gestión Pública. Lima: Marketing Consultores S.A.

Asamblea, N. C. (2008). Constitución de la República del Cuador. Quito: Asamblea Nacional.

Carrasco, J. B. (2001). Gestión de Procesos. Santiago, Chile, Ed. Evolución S. A. 
Celi de la Torre, P. (2019). Reforma a las normas de control interno [Reform to the internal control standards]. Quito, Distrito Metropolitano: Contraloría General del Estado.

Chacon, W. (2002). El Control Interno como Herramiento Fundamental Contable y Controladora de las organizaciones [Internal Control as a Fundamental Accounting and Controlling Tool for Organizations]. España: AECA.

Charry-Rodríguez, J. (2013). El control interno y los principios de evaluación de gestión en las entidades del Estado. Bogotá, Colombia.: Editorial Asociación colombiana de administradores.

Charry-Rodríguez. (2013). El Control Interno y los Principios de Evaluación de Gestión en las Entidades del Estado [Internal Control and the Principles of Management Evaluation in State Entities]. Bogotá: Asociación Colombiana de Administradores.

Chiavenato, I. (2004). Introducción a la Teoría General de la Administración [Introduction to the General Theory of Administration]. España: McGraw-Hill/Interamericana, editores.

Chiavenato, I. (2004). Introducción a la Teoría General de la Administración (Séptima Edición ed.). México: McGraw-Hill Interamericana.

Defensoría Pública (2018). Las metas y objetivos de las unidades administrativas de conformidad con sus programas operativos. Obtenido de https://n9.cl/z80a

Estrada, M. (2010). Sistema de Control Interno [Internal Control System]. Lima, Perú: Editorial Publicidad \& Matiz.

Fonseca, L. (2011). Sistemas de Control Interno [Internal Control Systems]. Lima: Publicidad \& Matiz.

Guerra, O. (2015). Propuesta de procedimientos de control interno aplicado a las áreas de contabilidad, talento humano y operativa de la empresa administradora de edificios Home Detail de la ciudad de Quito. https://n9.cl/3g35f

Guerrero, A. (2008). "La Teoría de la Administración Pública". México: Editorial Harla México.

Langrod, G. (2010). "Tratado de Ciencia Administrativa". Ed. Instituto de Estudios Administrativos -Escuela Nacional de Administración Pública. Madrid-España. 
Leonard, W. (2001). Evaluación de métodos y Eficiencia administrativa. México: Editorial Diana.

Martillo, L. (2008). Control interno de instrumentos financieros [Internal control of financial instruments]. Bogotá, Colombia: Ecoe.

Münch, L. (2010). Administración Gestión organizacional, enfoques y procesos administrativo [Administration Organizational management, approaches and administrative processes]. Méximo: Person Educación de Méximo, S.A. de C.V.

Muñoz L., P. (2014). La desconcentración del ejecutivo en el Ecuador el estado en el territorio y la recuperación de lo público [The deconcentration of the executive in Ecuador the state in the territory and the recovery of the public]. Quito: SENPLADES.

Murillo-Apolo, L., Narváez-Zurita, C., \& Erazo-Álvarez, J. (2019). Sistema de control interno con enfoque en la ISO 9001: 2015 en la bananera Monterrey. Revista Arbitrada Interdisciplinaria Koinonía, 4(2), 241-264. http://dx.doi.org/10.35381/r.k.v4i2.474

Ormaza-Rodríguez, S., Reyes-Reinoso, J., Cepeda-Luna, F., \& Torres-Palacios, M. (2020). Evaluación de riesgo y gestión administrativa en organizaciones pública [Risk assessment and administrative management in public organizations]. Revista Arbitrada Interdisciplinaria Koinonía, 5(3), 600-621. http://dx.doi.org/10.35381/r.k.v5i3.913

Poch, R. (2000). Manual de Control Interno [Internal Control Manual]. Cuenca: Gestión, Segunda Edición.

Pungitore, J. L. (2010). Sistemas administrativos y control interno. Barcelona, España.: Editorial Osmar D. Buyatti.

Reyes, H. J. (2012). Política y Administración. México.: Serie Praxis INAP.

Reyes, P. E., Narváez, C. I., Erazo, J. C., \& Giler, L. V. (2020). Configuración del impuesto a la patente municipal con base al ingreso de las actividades económicas. Caso: GAD Municipal de Pucará - Ecuador. Revista Espacios, 41(21), 197-211. 


\section{CIENCIAMATRIA}

Revista Interdisciplinaria de Humanidades, Educación, Ciencia y Tecnología

Año VII. Vol. VII. N¹2. Enero - Junio. 2021

Hecho el depósito de ley: pp201602FA4721

ISSN-L: 2542-3029; ISSN: 2610-802X

Universidad Nacional Experimental Francisco de Miranda (UNEFM). Santa Ana de Coro. Venezuela

Sandra Margoth Cabrera-Encalada; Juan Carlos Erazo-Álvarez; Cecilia Ivonne Narváez-Zurita Renán Teodoro Rodríguez-Pillaga

(C2021 por los autores. Este artículo es de acceso abierto y distribuido según los términos y condiciones de la licencia Creative Commons Atribución-NoComercial-Compartirlgual 4.0 Internacional (CC BY-NC-SA 4.0) (https://creativecommons.org/licenses/by-nc-sa/4.0/). 